\title{
Quality of Life among Parents of Mentally Challenged Children
}

\author{
Rishi Panday ${ }^{1 *}$, Nazish Fatima ${ }^{2}$
}

\section{ABSTRACT}

Background: A child born into family is usually received with joy and considered a blessing but when the child is handicapped and blessing is clearly mixed. Acceptance of child with mental handicap becomes difficult to parents and the whole family particularly when competence and achievement are very much valued in modern world. A parent shows a series of reactions after knowing that their child is disabled. These include shock, denial, guilt, sorrow, rejection and acceptance. Questions like 'why me?' 'How can it be?' keep arising without answers. This study was based on quality of life among parents of children with mentally challenged and it was gender based study. Aim: To study the gender differences in term of Quality of Life among parents of mentally challenged children. Methods and Material: It was cross sectional study conducted at RINPAS, Samples were recruited through purposive sampling technique. Semistructured interview schedule was developing to assess the demographics profile and Quality of life scales were administered on parents of children with mentally challenged. Results: Finding of this study showed that parents of male children have good Quality of Life in comparison to the parents of female children.

Keywords: Parents of mentally challenged children, Quality of Life.

The parents of children with female mentally challenged absolutely face more difficulties than parents of children with male mentally challenged, which in turn affect their quality of life. Many factors can influence the quality of life of the parents with mentally challenged children in family. Parents are in family who deal with the issues associated with child's disability and also maintain the household so it is very important for parents to take some time to care for themselves as individuals and getting enough sleep, eating regular meals, taking a short walk, and doing the things that they really enjoy. Parents having a child with mentally challenged experience a variety of stressors and stress reactions related to the child's disability and known to get impacted in many ways because of having a special child. These include feeling sad, depression at various stages of life and experiencing other emotional reactions.

\footnotetext{
${ }^{1}$ Ph.D. Scholar, Department of Social Work, J.M.I, New Delhi, India

${ }^{2}$ M.Phil. Scholar, Department of Psychiatric Social Work, RINPAS, Ranchi, India

*Responding Author

(C) 2016 I R Panday, N Fatima; licensee IJIP. This is an Open Access Research distributed under the terms of the Creative Commons Attribution License (http://creativecommons.org/licenses/by/2.0), which permits unrestricted use, distribution, and reproduction in any Medium, provided the original work is properly cited.
} 


\section{Quality of Life among Parents of Mentally Challenged Children}

Mental retardation refers to substantial limitations in present functioning. It is characterized by significantly sub average intellectual functioning, existing concurrently with related limitations in two or more of the following applicable adaptive skill areas like communication, home living community, use help and functional academics, and work. Mental retardation manifests itself before the age of 18 years (American Association on Mental Retardation, 1992).

\section{REVIEW OF LITERATURE:}

Wright (1988) studied attempt to evaluate the effects of the stresses of having a child with disabilities on the lives of their parents. The study compared the parents of children with disabilities to the parents of children without disabilities. It was found that the parents of children with disabilities did not differ from the other parents with respect to self image, and quality of life or life satisfaction. Geetha and Bhaskar (1993) found characteristics of the families of mentally retarded children and normal children. It was found that there is significant difference between two groups on all the variables studied. Lachiewicz (1994) conducted a study on Behavioural disorders in moderately mentally retarded children and relation to parental attitude. The result indicated that parents have a negative attitude towards their children with mental retardation. Simerman et al. (2001) find out that father's involvement in the lives of their young children with severe intellectual disability was highest in the areas of playing, nurturing, discipline and deciding services. Helgeson (2003) social support as a mitigating factor in relation to quality of life is not a new concept. Social support itself is a highly complex construct, with structural and functional measures. The perceived usefulness, reliability and flexibility of these supports can impact on caregiver's wellbeing and quality of life. Mungo et al. (2007) reported lower quality of life for parents of children with a pervasive developmental disorder when compared to parents of children with an intellectual disability, cerebral palsy, and non disabled children. When compared to autism, those parenting child with down syndrome reported less depression and stress and higher quality of life. Palmer et al. (2006). Sawyer (2010) found that when quality of life for caregivers of children with autistic spectrum disorder and an intellectual disability was compared to quality of life for those caring for a normally developing child. The research investigated differences of overall quality of life between groups. The result showed a difference in overall quality of life between groups. There Childs behaviour was found to have significant relationship with caregiver's quality of life. Dogar (2012) found that mothers had scored higher on quality of life in environment domain when their MR Child had the ability to do judgement in daily living; Fathers of the MR Child who can reason have scored higher on this domain than the fathers of the MR persons who cannot reason. Malhotra, Khan and Bhatia study in the same year revealed that parents of children with MR and autism seem to display a higher burden and impaired quality of life.

\section{Aim:}

- To study the gender deferens in term of Quality of Life among parents of mentally challenged children 


\section{Quality of Life among Parents of Mentally Challenged Children}

\section{METHODS AND MATERIAL:}

It was cross sectional study conducted at RINPAS, Samples were recruited through purposive sampling technique. Semi-structured interview schedule was developing to assess the demographics profile and Quality of life scales were administered on parents of children with mentally challenged.

\section{Inclusion Criteria for parents of Mentally Retarded Children}

1. Parents of mentally challenged children (children's age range was between 5-12 years, diagnosed as moderate mental retardation).

2. $\quad$ Age range of parents was between 20-45 years.

3. Parents who were able to comprehend the instructions.

4. Parents who gave consent to participate in the study.

\section{Exclusion Criteria for parents of Mentally Retarded Children}

1. Parents who had more than one mentally retarded child (diagnosed as mild, severe and profound level of mental retardation, having any co-morbid condition like cerebral palsy, mental illness, and vision or hearing impairment).

2. Parents having psychiatric illness and physical illness.

\section{Tools:}

\section{SOCIO-DEMOGRAPHIC DATA SHEET:}

It contains information about socio-demographic variables like age, sex, religion, education, marital status and domicile which is semi-structured, self-prepared Performa especially drafted for this study.

2. QUALITY OF LIFE SCALE (WHOQOL-BREF., Hindi version):

Hindi version of the WHOQOL-Brief has been derived from the original World Health Organization Quality of Life Scale. The Hindi version WHOQOL-Brief Scale is adopted by Saxena et al. (1998). WHOQOL-Brief is a short version of WHOQOL-100 questionnaires. WHOQOL-Brief has been tested in 15 centres including New Delhi and Chennai from India. WHOQOL-Brief contains 26 questions in 4 major domains (i.e. physical health, psychological health, social relationships and environment) to measure the quality of life. This scale emphasizes subjective experiences of the respondents rather than their objective life conditions. The alpha score of all domain ranges from 0.59 to 0.87 , coronach alpha of the all domains are 0.87, the factor loadings of the item ranges 0.52 to 0.84 WHOQOL-BREF is highly valid version across cultures.

1. Psychological domain - measures the self perception and cognitive ability

2. Physical domain - measures physical problems like joint pain, hearing, vision and sleep difficulties

3. Social domain - measures the level of social life, personal relations, social support, family acceptance and social interaction 


\section{Quality of Life among Parents of Mentally Challenged Children}

4. Environmental domain - measures living conditions, security, availability of medical assistance, opportunity of recreation and facilities

Table-1: Socio-demographic variables between parents of Mentally Challenged Children

\begin{tabular}{|c|c|c|c|c|c|}
\hline \multirow{2}{*}{\multicolumn{2}{|c|}{ Variable }} & \multicolumn{2}{|l|}{ Group } & \multirow{2}{*}{ df } & \multirow{2}{*}{$\chi^{2}$} \\
\hline & & \multirow{2}{*}{$\begin{array}{l}\text { Male } \\
18(60 \%)\end{array}$} & \multirow{2}{*}{$\begin{array}{l}\text { Female } \\
15(50 \%)\end{array}$} & & \\
\hline \multirow{2}{*}{ Gender } & Male & & & \multirow{2}{*}{1} & \multirow{2}{*}{$1.03 \mathrm{NS}$} \\
\hline & Female & $12(40 \%)$ & $15(50 \%)$ & & \\
\hline \multirow{2}{*}{ Marital Status } & Married & $27(90 \%)$ & $29(98.3 \%)$ & \multirow{2}{*}{1} & \multirow{2}{*}{$1.01 \mathrm{NS}$} \\
\hline & Widow & $3(10 \%)$ & $1(3.3 \%)$ & & \\
\hline \multirow{5}{*}{ Education } & Primary & $3(10 \%)$ & $9(30.3 \%)$ & \multirow{5}{*}{5} & \multirow{5}{*}{ 23.8NS } \\
\hline & Secondary & $9(20 \%)$ & $9(30.0 \%)$ & & \\
\hline & H. Secondary & $11(36.7 \%)$ & $2(6.7 \%)$ & & \\
\hline & Graduation & $7(23.3 \%)$ & $1(3.3 \%)$ & & \\
\hline & PG and Above & $0(0 \%)$ & $1(3.3 \%)$ & & \\
\hline \multirow{3}{*}{ Domicile } & Rural & $24(80.0 \%)$ & $21(70 \%)$ & \multirow{3}{*}{2} & \multirow{3}{*}{$4.28 \mathrm{NS}$} \\
\hline & Semi-urban & $3(10.0 \%)$ & $3(10 \%)$ & & \\
\hline & Urban & $3(10 \%)$ & $6(20 \%)$ & & \\
\hline \multirow{4}{*}{ Occupation } & Farmer & $21(70 \%)$ & $18(60 \%)$ & \multirow{4}{*}{4} & \multirow{4}{*}{$21.60 \mathrm{NS}$} \\
\hline & Pvt.Job & $3(10.0 \%)$ & $6(20.0 \%)$ & & \\
\hline & Govt.Job & $3(10 \%)$ & $3(10 \%)$ & & \\
\hline & Others & $3(10.0 \%)$ & $3(10 \%)$ & & \\
\hline \multirow{3}{*}{ Patient's education } & Primary & $12(40 \%)$ & $12(40 \%)$ & \multirow{3}{*}{2} & \multirow{3}{*}{ 2.32NS } \\
\hline & Secondary & $9(30 \%)$ & $6(20 \%)$ & & \\
\hline & Other & $9(30 \%)$ & $12(40 \%)$ & & \\
\hline
\end{tabular}

NS $=$ Not Significant

Table 2: Quality of life among parents with mentally challenged children

\begin{tabular}{|l|l|l|l|}
\hline \multirow{2}{*}{ Variable } & \multicolumn{2}{|l|}{ Group } & \multirow{2}{*}{ T } \\
\cline { 2 - 3 } & $\begin{array}{l}\text { Male (N=40) } \\
\text { Mean } \pm \text { SD }\end{array}$ & $\begin{array}{l}\text { Female N=40) } \\
\text { Mean } \pm \text { SD }\end{array}$ & $5.46^{* *}$ \\
\hline PHYSICAL & $26.50 \pm 2.97$ & $21.54 \pm 3.23$ & $4.70^{* *}$ \\
\hline PSYCHOLOGICAL & $20.36 \pm 4.66$ & $17.23 \pm 3.57$ & $4.28^{* *}$ \\
\hline SOCIAL & $10.70 \pm 2.78$ & $7.16 \pm 2.37$ & $3.62^{* *}$ \\
\hline ENVIRONMENTAL & $24.54 \pm 3.98$ & $19.63 \pm 4.48$ & $4.47 * *$ \\
\hline Total Quality of Life & $82.10 \pm 14.39$ & $65.56 \pm 13.65$ & \\
\hline$* *=$ significant at 0.05 Level & $* *=$ significant at 0.01 Level & & \\
\hline
\end{tabular}

$* *=$ significant at 0.05 Level $\quad * *=$ significant at 0.01 Level

(C) The International Journal of Indian Psychology, ISSN 2348-5396 (e)| ISSN: 2349-3429 (p) | 155 


\section{Quality of Life among Parents of Mentally Challenged Children}

Table 1 shows the demographic details of parents of mentally challenged children. The findings of the above table indicate that there is no gender difference find in terms of socio-demographic details. In both group no significant difference is find.

Table 2 show the details of Quality of life among parent of mentally challenged children. The mean score of Physical health of parents of males child is $26.50 \pm 2.97$ and parents of female child are 21.54 \pm 3.23 . The $t$ vale of Physical health is 5.46 and it is most significant at 0.01 levels. The mean score of Psychological health of parents of male child is $20.36 \pm 4.66$ and a parent of female child is $17.23 \pm 3.57$. The $t$ vale of Physical health is 4.70 and it is most significant at 0.01 levels. The mean score of Social health parents of male child is $10.70 \pm 2.78$ parents of female child is 7.16 \pm 2.37 . The $t$ vale of Physical health is 4.28 and it is most significant at 0.01 levels. The mean score of Environmental health of parents of male child is $24.54 \pm 3.98$ parents of female child is 19.63 \pm 4.48 . The $t$ vale of Physical health is 3.62and it is most significant at 0.01 levels. The mean score of Quality of Life of parents of male child is 82.10 \pm 14 .39parents of female child is 65.56 \pm 13.65 . The $t$ vale of Physical health is 4.47 and it is most significant at 0.01 levels.

\section{DISCUSSION \& CONCLUSION:}

Findings of the study show that no significant difference found in socio-demo graphic detail between both groups. Findings of this study indicate that Physical, Psychological, Social and Environmental health of better parents of male mentally challenged children in comparison to female mentally challenged children. Parents of children with mental retardation and autism seem to display a higher burden and a significant impairment in their quality of life. These finding must be taken into account in policy making to provide better and more specific supports and interventions for this group of diseases. More attention should be given to parents' (and in particular mothers') needs. Social support and different coping strategies should be developed to respond positively to individual changing needs and in buffering parents from the stress of having a child with disability. New research should be conducted to measure the effectiveness of these strategies. In addition, effective and sustainable psycho-social programs are needed to provide necessary support for the special needs of the children and their families. The study concluded that the parents of children with mental retardation had average quality of life in physical, psychological, social and environmental aspects and poor quality of life in financial aspect. This emphasizes parents of children with mental retardation face financial burden and also diminished quality of life in social aspect. Thereby health care professional especially nurses must focus on improving the quality of life and their survival.

\section{FUTURE DIRECTIONS AND IMPLICATION:}

The future studies must attempt to carry out other social aspect which is related to parents of mentally challenged children. The scope for intervention by mental health professionals, especially, psychiatric social workers in planning and delivering adequate therapeutic services in the clinical context.

(C) The International Journal of Indian Psychology, ISSN 2348-5396 (e) | ISSN: 2349-3429 (p) | 156 


\section{Quality of Life among Parents of Mentally Challenged Children}

\section{REFERENCES:}

Dogar, I. M., Haider, N., Arshad, M., \& Afeal, S. (2012). The Relationship between the Characteristics of Mentally Retarded Persons and the Quality of life Perception of their Parents. Annals of Punjab Medical College, 6(1), 67-71.

Geetha, C. V., \& Bhaskar, G. (1993). A study of certain characteristics of the families of mentally retarded children in comparison to families of normal children. Indian Journal of Applied Psychology, 30(1), 25-29.

Helgeson, V. S. (2003). Social support and quality of life. Quality of life research, 12(1), 25-31.

Lachiewicz, A. M., Spiridigliozzi, G. A., Gullion, C. M., Ransford, S. N., \& Rao, K. (1994). Aberrant behaviors of young boys with fragile X syndrome.American Journal on Mental Retardation.

Mungo, D., Ruta, L., Arrigo, V., \& Mazzona, L. (2007). Impairment of quality of life in parents of children and adolescents with pervasive developmental disorder. Health and Quality of Life Outcomes, 5(22), 1-9

Palmer, R. F., Blanchard, S., Stein, Z., Mandell, D., \& Miller, C. (2006). Environmental mercury release, special education rates, and autism disorder: an ecological study of Texas. Health \& Place, 12(2), 203-209.

Sawyer, M. G., Bittman, M., La Greca, A. M., Crettenden, A. D., Harchak, T. F., \& Martin, J. (2010). Time demands of caring for children with autism: What are the implications for maternal mental health?. Journal of Autism and Developmental Disorders, 40(5), 620628.

Simmerman, S., Blacher, J., \& Baker, B. L. (2001). Fathers' and mothers' perceptions of father involvement in families with young children with a disability. Journal of Intellectual and Developmental Disability, 26(4), 325-338.

Wright, B.A. (1988). Attitudes and the fundamental negative bias: Conditions and corrections. In H.E.Yuker (Eds.), Attitudes toward persons with disabilities (pp.3-21) New York: Springer

How to cite this article: R Panday, N Fatima (2016), Quality of Life among Parents of Mentally Challenged Children, International Journal of Indian Psychology, Volume 3, Issue 3, No. 11, DIP: 18.01.205/20160303, ISBN: 978-1-365-21307-6 